\title{
SEXUAL AND REPRODUCTIVE HEALTH NEEDS OF ADOLESCENT SECONDARY SCHOOL GIRLS IN BAYELSA STATE
}

\author{
Helen Idubamo Wankasi (PhD) ${ }^{1}$ and Efeunu Efemena Nora ${ }^{2}$ \\ ${ }^{1}$ Department of Community Health Nursing, Faculty of Nursing Sciences, Niger Delta \\ University, Wilberforce Island, Bayelsa State, Nigeria \\ Email: hidubamo@gmail.com; Orcid.org 0000-0002-8403-5555 \\ ${ }^{2}$ Federal Medical Center Yenagoa. Bayelsa State, Nigeria
}

Cite this article:

Helen I.W., Efeunu E.N. (2021), Sexual and

Reproductive Health Needs of Adolescent Secondary School Girls in Bayelsa State. African Journal of Health, Nursing and Midwifery 4(6), 84-100. DOI: 10.52589/AJHNMYAIE6ATL.

\section{Manuscript History \\ Received: 5 Oct 2021 \\ Accepted: 23 Oct 2021 \\ Published: 4 Dec 2021}

Copyright $\odot 2020$ The Author(s). This is an Open Access article distributed under the terms of Creative Commons AttributionNonCommercial-NoDerivatives 4.0 International (CC BY-NC-ND 4.0 ), which permits anyone to share, use, reproduce and redistribute in any medium, provided the original author and source are credited.
ABSTRACT: Introduction- Pinpointing sexual and reproductive health needs from the students` perspective is a key step towards prevention of avoidable global adolescents`death and promotion of health. The purpose of this article was to explore the sexual and reproductive health needs of adolescent secondary school students in Bayelsa State. Method-A descriptive qualitative design was adopted for this study using the purposive sampling technique with a sample of 10 participants in one public secondary school. The Source of data was a semi-structured interview guide and a voice recorder. Data was analyzed thematically in six sequential steps. Findings- Two (2) themes, sexual and reproductive health needs of adolescents, methods of sexual health dissemination and five (5) sub-themes emerged. Conclusion-Findings indicate that the public-secondary school adolescent girls require education on; menstrual cycle, prevention of sexually transmitted infections, Human ImmunoDeficiency Virus /Acquired Immune Deficiency Syndrome, as well as on appropriate use of different types of contraceptives from established centres for sexual and reproductive health services. To ensure the public secondary school girls have access to the services and utilize the services, this study recommends the dare need to adopt different methods to disseminate sexual and reproductive health information to reach the secondary school girls to prevent avertable illnesses and deaths.

KEYWORDS: Sexual, Reproductive Health, Needs 


\section{INTRODUCTION/ BACKGROUND OF STUDY}

Sexual and reproductive health is a state of complete physical, mental and social well-being in all matters relating to the reproductive system function and general well-being according to the United Nation`s Population Fund, (UNPFA) (2021) update. The UNPFA, (2021) and Phipps, (2008) focus of study is that good sexual and reproductive health should embrace efforts to reduce avertable deaths and illnesses to the barest minimum; ensure quality sexual and reproductive health services such as contraceptive services, discourse sexually transmitted infections (STI) and cervical cancer as well as violence against the opposite sex. Thus, pinpointing sexual and reproductive health needs from the students" perspective is a key step towards the prevention of avoidable global adolescent ' death and healthcare promotion in school (Efeunu \& Wankasi, 2020). Yet, the entire concept is seemingly trivialized (given little attention in both low and middle-income countries) (United Nations 2012). This study explores the sexual and reproductive health needs of adolescents (secondary school students) in Bayelsa State.

The World Health Organization (WHO) (2018) and Cleveland Clinic (2018) reviewed an anecdotal article that referenced the American Academy of Child and Adolescent Psychiatry (2018). The article termed adolescents as people seen between 10 to 19 years' age range and labelled the adolescent as a unique period of special needs. Cleveland Clinic (2018) medical professionals also found out that adolescents undergo three crucial developmental phases namely:-early adolescence which is the growth spurt with early sign of maturation from 10-14: middle adolescence is the appearance of primary sexual features, where changes in the organs unswervingly connected to reproduction occur, whereas late adolescence/young adulthood, is when secondary sex physiognomies, that is, bodily signs of sexual maturity that do not directly involve reproductive organs shows. The great majority of adolescents are, therefore, included in the age-based definition of "child", adopted by the Convention on the Rights of the Child, as a person under the age of 18 years.

Globally, at least seventy thousand $(70,000)$ adolescents die each year on account of complications from sexual and reproductive health-related issues (United Nations 2015). Shiffman, Kunnuji, Shawar and Robinson (2018) and the United Nations (2015) pose it that, adolescents face death and a number of considerable reproductive risks due to their biological makeup, lifestyle and environment as well as sundry factors. For instance, as at UNAIDS (2016) in its "Global AIDS Update Geneva" estimated 20\% of new HIV infections to secondary school age and above (i.e., adolescent girls and young women aged 15 to 24years), even as adolescents comprised only $11 \%$ of that population in 2016.

Consequent upon these, the UNESCO Institute of Statistics, (2019) quoted in Wankasi, Jerusalem and Chukwuere (2021) also stated that reproductive health services are needed to prevent the aforementioned risks. To maintain this assentation, a statement made at the international conference on population and development (which was a new era in reproductive health) worldwide emphasized that, adolescents have needs that are unique to those of adults. Therefore, in consonance with this statement, countries were enjoined to identify areas of dare need and proffer solutions if so desire. In compliance with this directive, countries, states and by extension various schools developed some defined critical sexual reproductive health education needs. According to James et al. (2018), for a service to be considered as adolescent and youth-friendly, such service must have a component of at least a, c, d, f and i from the following 
ten (10) needs:

"a. administrative system support for the effective provision of adolescent and youthfriendly health services. $b$. Strategies and practices that support the privileges of youngsters. c. applicable adolescent health services must be available and accessible. $d$. The clinics should have a physical environment conducive to the provision of adolescent-friendly health services. e. The clinic must have adequate drugs, supplies and equipment necessary to provide the essential service package for youth-friendly healthcare. $f$. Provision of relevant information, education and communication (IEC) promoting behaviour change consistent with the essential service package. g. There must be systems in place to train and develop staff to provide effective adolescentfriendly health services viii. Adolescents must receive adequate psychosocial and physical assessments $h$. Adolescents must receive individualized care based on standard case management guidelines/protocols. $i$. The clinic should provide continuity of care for adolescents: proper referral systems must be in place”(James et al., 2018).

Not only that, the scholars further in a bar chart presented other sexual and reproductive services needed to provide health and well-being for the adolescent secondary school students still in the same study entitled "assessment of adolescent and youth-friendly services which are core-needs in this context in primary healthcare facilities in two Republic of South-Africa provinces as below.

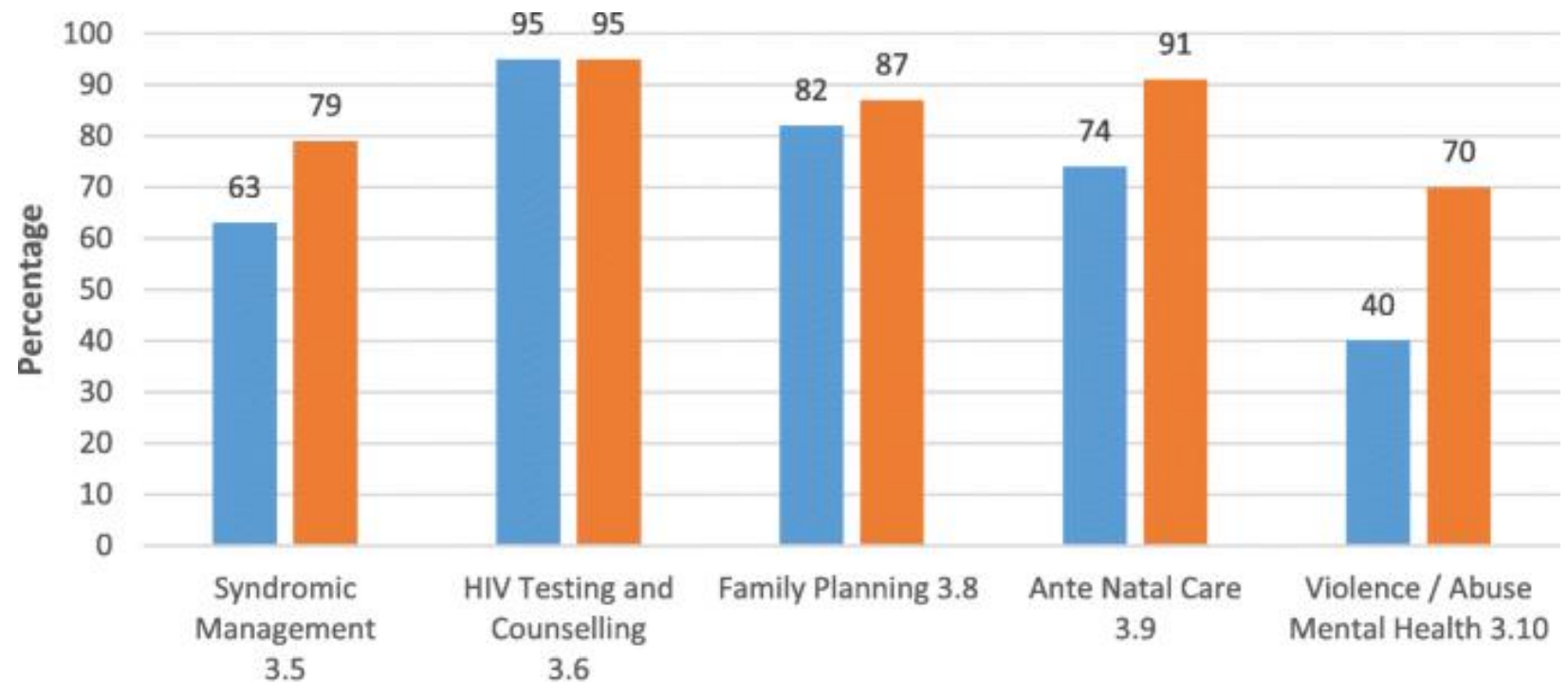

Sexual, Reproductive and Mental Health Services

mauteng $\quad$ in North-West

Figure 1: Source: An excerpt from James et al., (2018) 
Judging from these outlined essential sexual and reproductive health services, there is a desperate need to ascertain that these helpful needs are available in Bayelsa State, Nigeria to further ensure adolescents` satisfaction, constancy and educate the adolescents for the use of such accessible services. Otherwise, secondary school students might be indifferent because they may be naïve of the existence of such needs and engage in acts inimical to their health.

Besides these, in the Middle East, such as Iran, the concept of reproductive and sexual health for adolescents has not been given its pride of place as a result of several factors in recent years. Regardless, policymakers in Iran healthcare system have felt the need for designing studies that include the needs of adolescents more than ever in order to use these results to propose suitable methods for satisfying the needs that are acceptable according to the local culture (MirzaiiNajmabadi, et al, 2014), considering the fact that people's needs are based on their cultural, social and economic situations in the society and are also based on people's shared understanding, experience and beliefs, there is need to adopt the proposed methods ((MirzaiiNajmabadi, et al., 2014).

Similarly, not too long, Asante, (2016) added his voice that adolescents' reproductive health needs and problems are yet to receive adequate attention especially in developing countries like Nigeria, despite the recognition of youth-friendly reproductive health services as a way of improving their access and utilization of reproductive health services in order to achieve quality reproductive health/life. Sex education provides young people with the necessary information to make informed choices regarding their sexual and reproductive health - (Sexuality Information and Education Council of the United States (SIECUS, 2012; FSE, 2012).

Though plausible, the Global Health e-learning Center (2017) identified acts to attain quality sexual and reproductive health being constrained by inadequate access to and inequitable distribution of quality reproductive health education needs. The agency affirmed that these have resulted in the high prevalence of sexual and reproductive health problems, especially among adolescents.

In another perspective, adolescents in secondary school constitute over $35 \%$ of the Nigerian population have been found to be highly vulnerable to antisocial behaviours such as violent sexual activities amongst others (DeLamater, 2002). The vulnerability is that; many Nigerian societies have reservations about discussing with their children, issues relating to sex and even those who attempted was not in-depth (Eko, Abeshi, Osonwo and Offiong, 2013). As such, adolescent school girls are un or misinformed on sex and reproductive issues throughout their lifetime with attendant consequences (Eko, et al., 2013). Therefore, to enable researchers to gain understanding and from a wide range of people, it is key to elicit the opinion of secondary school adolescents girls who are presumed to have first-hand knowledge of their needs. Again, helpful connexions of adolescents and peers in schools could reduce the prevalence and detriment of unsafe activities; they can also embolden health-promoting behaviours among adolescents. The development of adolescents is also influenced by their socio-physical environment.

\section{Problem Statement}

Good sexual and reproductive health is a state of complete physical, mental and social wellbeing in all matters relating to reproductive issues. To achieve these means adolescents must have the freedom to decide when, with who and how often to engage in sexual acts through 
access to accurate information regarding available services, access to such services that are safe, effective, affordable and acceptable for adolescents to make informed choices. These will not only inform students but will also empower and enable them to protect themselves from sexually transmitted infections.

These are not yet tenable, UNFPA (2014) found in a global perspective that, at the onset of adolescence, there is often time a number increase in new vulnerabilities to human rights abuses in millions of students, in terms of sexuality, millions of girls are coerced into uninformed sexual acts; marriage, which exposes the students at risk of unwanted pregnancies/ unsafe abortions and childbearing, which exposes the adolescent students to dangerous childbirth as well as sexually transmitted infections (STIs) such as HIV/AIDS. UNFPA (2014) also stated that these vices do not affect only the schoolgirls, but also the adolescent boys, thus making them vulnerable as well. This is a sequel to the fact that students face barriers to reproductive health information and care. Even those able to find accurate information about their health and rights may be unable to access the services needed to protect their health. Not only that, in Guttmacher Institute fact sheet (2017) and Lindberg, Maddow-Zimet and Boonstra (2016) in America, it is stated that declines in formal sex education were concentrated among young people residing in rural areas-71\% to $48 \%$ among females, and from 59\% to $45 \%$ among males, meaning there is a disproportion between male and female students and rural and urban dwellers. In 2011-2013, only 50\% of females and 58\% of males aged 15-19 reported having received any form of education as illustrated below in figures $2 \mathrm{a}$ and $2 \mathrm{~b}$.

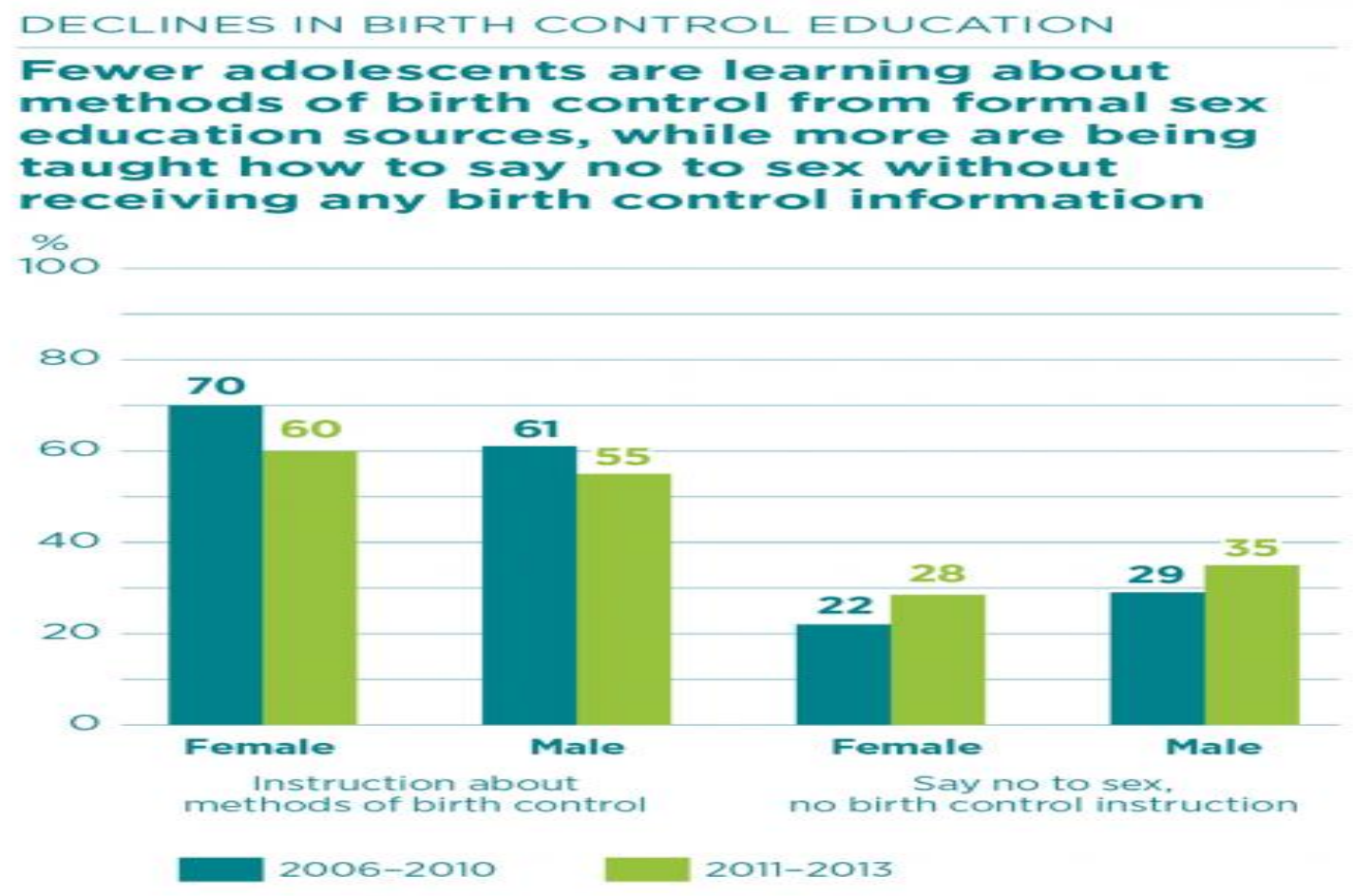
Institute fact sheet (2017). 

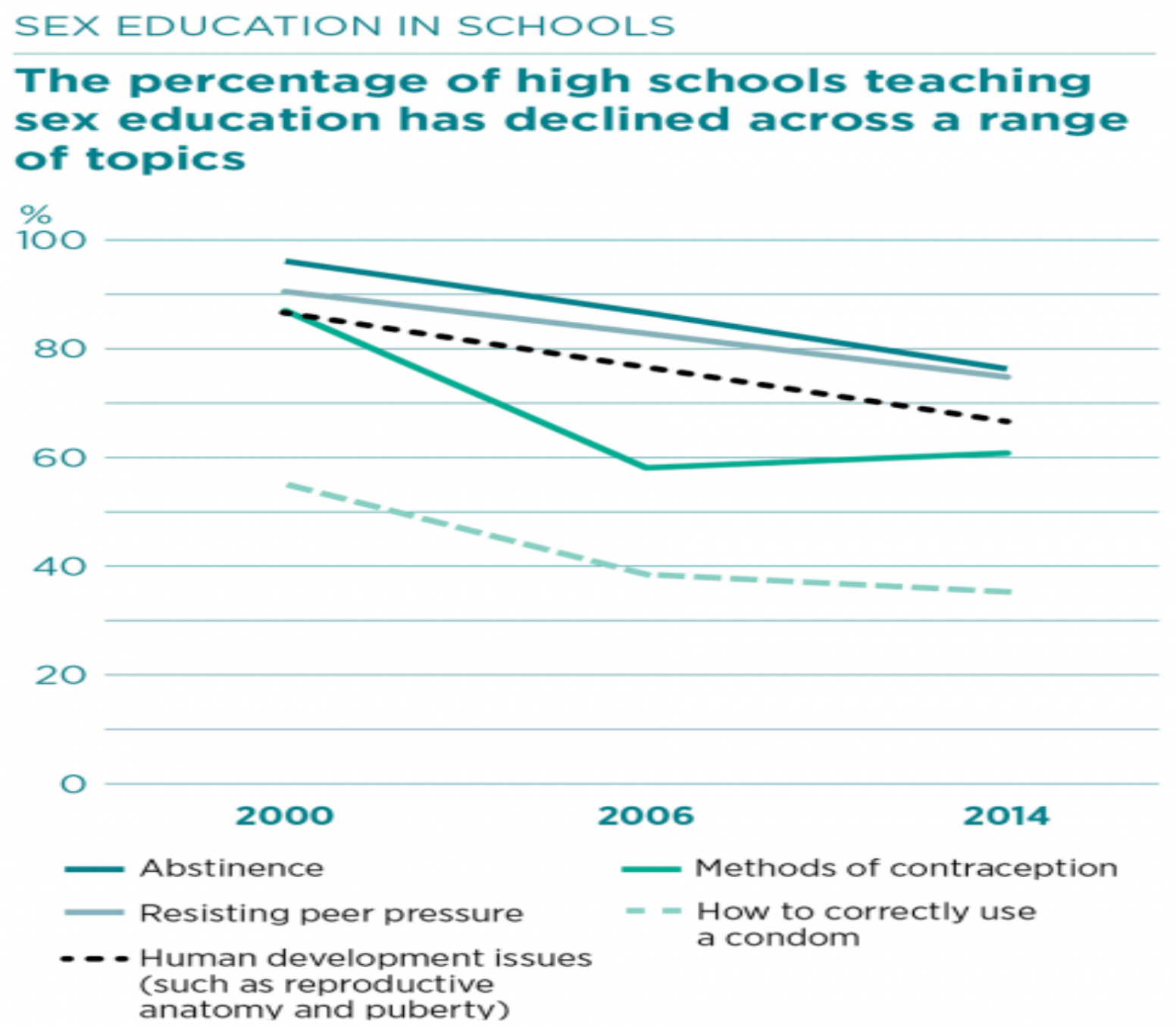

$2006 \quad 2014$

- Methods of contraception

- - How to correctly use a condom

wwW.guttmacher.org

Figure 2b: Percentage of high schools teaching sex education decline rate. Source: An excerpt from Guttmacher Institute fact sheet (2017).

Here in Bayelsa State, which is predominantly a rural State in Nigeria, there are 206 public secondary schools and 93 private secondary schools, which is huge, but there are no identifiable adolescent and youth-friendly centres meant to promote adolescents in secondary schools well-being and health, and it has a significant impact on the group under review for the following reasons:- the centres would provide access and care even without the consent of their parents and would also provide counselling services at no cost or subsidized rate. If the trend is continuous, more adolescents would stand the risk of unintended pregnancies with its attendant consequences, sexual violence and STIs, which in turn can result in ill-health, absenteeism and school dropouts. School dropout will increase educational inequalities and poverty contrary to the main focus of universal health coverage. Therefore, there is a need to explore sexual and reproductive health needs with the following question "What are the sexual 
and reproductive health needs of adolescents in community secondary school Amassoma, Bayelsa state"?

A cross-sectional qualitative study conducted way-back by Olfati and Aligholi (2008) to assess the sexual health needs of adolescents and explore their attitude towards current services available. The study was conducted in Wakiso district, central Uganda with 20 focused groups and was analysed using descriptive statistics and chi-square tests. Findings show that most adolescents had expressed the need for education on reproductive health in order to resolve their problems and asked for training in these areas. According to the recommendations of the World Health Organization (WHO), informing teenagers about reproductive health is one of the main elements in starting national plans for improving teenagers' health situation on one hand. On the other hand, according to the reproductive rights in the national law which accepts the international documents related to human rights and the United Nations, access to the highest standards of reproductive and sexual health and decision-making about reproduction without any discrimination, pressure and violence is among teenagers' basic rights. In recent years and due to great social and cultural changes, the marriage age has increased in Iran which has increased the probability of sexual activities outside of marriage and the possibility of infectious and sexually transmitted diseases such as Human Immunodeficiency Virus (HIV). Therefore, educating adolescents regarding reproductive health not only won't cause stress and sexual promiscuity but instead, access to proper and timely information from parents can prevent risky sexual relations and premature sexual relations. This positive effect has been emphasized in various studies. Some Iranian researchers in their studies concluded that health education has a significant effect on increasing the rate of knowledge, attitude and performance of females towards maturity health. Thus, maturity education should be emphasized in order to improve the health behaviours of girls during adolescence (Hajikazemi et al 2014).

Furthermore, a similar cross-sectional study was carried out in Nepal among 3041 adolescents of age 15-19 years residing in the rural areas of 4 districts of Nepal in 2011 concluded that the participants had moderate reproductive and sexual health knowledge. The same study revealed male respondents having better knowledge compared to female respondents regarding SRH issues like HIV/AIDS. Regarding the source of SRH information, the respondents mentioned their parents, friends/peers, school books/ teachers and media like TV, cinema and radio as their source of information. The most popular source which was mentioned by more than $90 \%$ of the respondents was media, after that was parents with around $53 \%$. Likewise, $50 \%$ also answered school books as their source of reproductive health education (Simkhada et al. 2012).

\section{RESEARCH METHODOLOGY}

An exploratory descriptive qualitative design was adopted for this study to give an insight into the reproductive health education needs of adolescent public school girls in Amassoma Community, Bayelsa State. Successful utilization of this method in similar studies has been documented (Shakour, Salehi \& Yamani, 2018, Ingham-Broomfield, 2015, Kothari, et al., 2016). The setting of this study is the community secondary school in Amassoma; it is located at the centre of the community close to the university. Though the school premises is fenced, not too firm a security system around the school, in effect, students can easily have the leverage of moving freely in and out of school premises without an effective monitoring system. The Lshaped only storey building comprising of about 20 classrooms including the staff offices and 
conveniences. These characteristics make the students vulnerable to negative vices, inappropriate sexual and reproductive health behaviours, thus the need to conduct this study there.

Population/ Sample Size: The population consists of students in a senior secondary school which include 52 eligible (willing, public secondary school SSS2\&3) students in Amassoma. This was chosen on the premise that the majority of adolescents are within the age of $18-20$ years and may have been involved in a sexual relationship and therefore capable of providing necessary information for the study. The sample size was aimed at data saturation which was achieved at the tenth $\left(10^{\text {th }}\right)$ participant when no new information was further elicited according to Creswell, (2014), Ingham-Broomfield, 2015). The breakdown was as follows; 6 from ss3, and 4 from ss2. Non-probability purposive sampling was adopted due to prior knowledge of the participants. A voice recorder and a two sectioned semi-structured interview guide were the instruments for data collection (Creswell, 2014). Section 1 is the demographic section, whereas, section 2 covers the objective?

\section{Procedure for Data Collection}

It was a step-by-step process in data collection as prescribed (Creswell, 2014) as follows:

Upon receipt of an introductory letter from the Dean Faculty of Nursing Sciences, the letter was presented to the gatekeeper (Vice-principal (VP)) in Community secondary school Amassoma. The VP contacted the school physical and health education teacher, who in turn contacted the various class teachers from SSS2 and SSS3 aimed at informing students of the study that it was for purely academic purposes. As such, those willing student-participants above 18 years consented for themselves, whereas, those few below 18 years in SSS2 were consented for by the class teachers. Thereafter, the teacher also picked those students that were able to respond to the questions put forwarded appropriately.

Individual interviews were conducted privately in classrooms during recess, which lasted 20 mins since they had limited break periods. Key questions were asked and further probing was done to clarify unclear issues. At the $8^{\text {th }}$ participant, data saturation was reached when no new information was further elicited from students, thus the researcher added two more to be certain.

\section{Trustworthiness and Rigor of the Instruments}

Trustworthiness as proposed by Guba and Lincolin (1989) also used by Ghafouri, and Ofoghi, (2016) was achieved through-:

Credibility- the credibility of the instrument was ascertained by focusing on the research objectives through the use of a structured interview guide and engagement with the participants. Transferability- was achieved because these research work findings can be adopted in similar settings since studies of this nature can be carried out in similar settings. For conformability, the researcher made copies of the instruments available to the supervisor and other research experts. Comments and suggestions received were used to modify the final draft of the instrument before it was finally administered. Moreover, the step-by-step methods of data collection and analysis are clearly demonstrated. 


\section{Ethical Consideration}

The following ethical principles guiding research were considered in the course of carrying out this study.

Permission: A notice of approval number: 089-490257 was obtained from the Ministry of Health. A letter of introduction from the Faculty of Nursing Sciences, Niger Delta University to the selected schools and permission to conduct the research study was obtained from the various authorities in charge of the schools. This feat enabled the researcher to gain access to the participants and information needed for the study.

Informed Consent: Participants were fully informed of the research aims, and potential benefits and disadvantages. Participants were given an approved informed consent form to sign after they are fully informed about the study. They were encouraged to ask questions where they are not clear and only give information that they feel comfortable with.

\section{Confidentiality and anonymity}

Information passed to the researcher was used purely for the research purpose and was not revealed to others not directly involved in the study. The researchers tagged Participants (P1,2,3 etc) rather than names to ensure anonymity.

Respect for the autonomy of participants was respected, therefore, participants were informed of their right not to answer any question or willing to withdraw at any point.

\section{Data Analysis}

In this study, Creswell (2014) and Xia and Gong (2015) six steps of thematic data analysis using a deductive approach were carried out thus:

Step 1. The researcher listened and transcribed the raw data.

Step 2. In step two, the transcript was repeatedly read over and over again, then code-able areas were highlighted having objectives in mind.

Step 3: In this step, categories were created, still in line with the objections

Step 4: In step four, the researcher coded specific statements to form sub-themes

Step 5: sub-themes were regrouped to form themes

Step 6. Researchers interpret/discussed results all as proposed by Creswell, (2014).

\section{Findings}

In this segment, findings were analysed, presented and discussed with a literature control.

A total of 10 students were interviewed for the study to gain knowledge of the sexual and reproductive health needs of adolescents in Amassoma, Bayelsa State. Incidentally, all responses were elicited from female participants in SS2 - SS3. The mean age was 18 with a range of $16-20$ years. Participants are all Christians, residents in Amassoma and attend the public secondary school in Amassoma, Bayelsa State. 
The significance of this data is that all participants regardless of their demographic data expressed their need for reproductive health education. Findings related to the objectives have two (2) main themes sexual and reproductive health needs and methods of sexual health dissemination and five (5) sub-themes.

\section{Table 1: Summary of Findings}

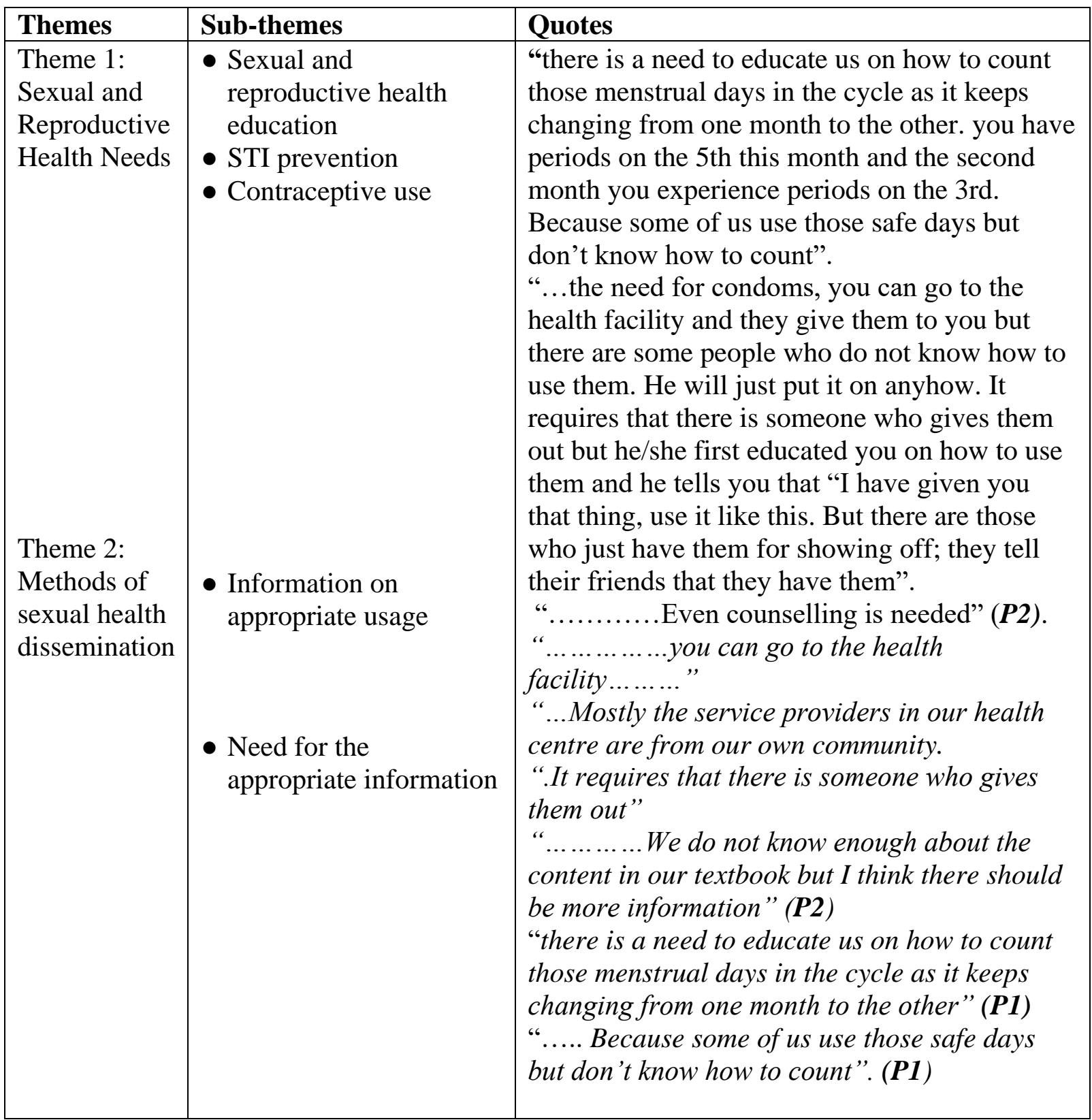




\section{Themes 1: Sexual and Reproductive Health Needs}

Three sub-themes emerged from this theme namely:

Sub-theme 1. Sexual and reproductive health education

Two (2) participants attest that sexual and reproductive health needs continue to be an issue of concern amongst adolescent public-school girls. One of such needs is education on the menstrual cycle and how the calendar method could be applied in the prevention of pregnancy. Other needs include the provision of condoms and counselling that is needed to prevent STIs including HIV/AIDs, unwanted pregnancy and psychosocial problems associated with the sexual and reproductive health of the adolescent girl. Below is an example of participants' responses:

"There is a need to educate us on how to count those menstrual days in the cycle as it keeps changing from one month to the other. You have periods on the 5th this month and the second month you experience periods on the 3rd. Because some of us use those safe days but we don't know how to count". (Participant no 1)

“.....We also need things that can prevent us from HIV/AIDS and also, we need pregnancy control things like condoms, so that it can save some youths. Even counselling is needed" (P2)

Sub-theme 2. Sexually transmitted infections (STI) prevention

At least six (6) out of the ten (10) participants affirmed that sexually transmitted infections (STI) prevention is a Sexual and Reproductive Health Needs of public-school adolescent girls. Below are two quotes to that effect.

“...HIV and STIs are not only sexual health issues of the people of our age. There are unwanted pregnancies and also some psychological problems associated with sexual health like during periods (menstruation) girls have to suffer from pain and also other mental pressure. But in our sex education class, when teachers start talking about menstruation, everyone laughs. We cannot concentrate on it and we have to know it ourselves. We don't know enough about the content in our textbook but I think there should be more information" (P2)

“.....In our textbook, there is something about sexual disease and HIV and I think that is not enough to live a healthy sexual life because HIV is the major sexual health problem."(P5).

Sub-theme 3. Contraceptive use and information on appropriate usage

Two participants expressed their unmet needs and knowledge of contraception during the interview. Below is evidence of their responses:

"...the need for condoms, you can go to the health facility and they give them to you but there are some people who do not know how to use them. He will just put it on anyhow. It requires that there is someone who gives them out but he/she first educated you on how to use them and he tells you that "I have given you that thing, use it like 
this. But there are those who just have them for showing off; they tell their friends that they have them" (P3)

“...Mostly the service providers in our health centre are from our own community. They personally know us. In that situation, it is difficult to go there and receive any service relating to sexual health. Even I cannot go there if I need a condom" (P3)

\section{Theme 2: Methods of sexual health dissemination}

Two sub-themes emerged from this theme as viz: information on appropriate usage and the need for the appropriate information.

Sub-theme 1: Information on appropriate usage

A number of participants mentioned the need for adequate information on the appropriate usage of facilities and services. For instance, the quote made on contraceptives could be inferred from other services available, yet youths are naïve in terms of their usage. See the quote below

“ you can go to the health facility and they give them to you but there are some people who do not know how to use them.... "(P3).

For information to be effectively used, there are different approaches or through which the information could be transmitted which participants mentioned counselling. See the quotes below.

“.............even counselling is needed” (P2).

Again, participant (3) also mentioned the need for students to be given sexual and reproductive health information through either the students reaching out to the providers at the healthcare facility as a method or the healthcare provider reaching out to the students and educate the students. See the quote below

“...............you can go to the health facility ... ,"(P3)

"...Mostly the service providers in our health centre are from our own community" (P3).

Sub-theme 2: The need for the appropriate information dissemination. This sub-theme was also stressed by participants. To put it differently, participants reiterated the need to disseminate sexual and reproductive health information. Below are samples of some of the quotes.

"............We do not know enough about the content in our textbook but I think there should be more information" (P2)

"there is a need to educate us on how to count those menstrual days in the cycle as it keeps changing from one month to the other" (P1)

“.... Because some of us use those safe days but don't know how to count”. (P1) 


\section{DISCUSSION}

The main objective of this study was achieved because participants provided the needed answers to the questions as seen in the two broad themes that emerged.

The themes 1: Sexual and Reproductive Health Needs as earlier stated had three sub-themes. The first was sexual and reproductive health education

Participant's responses are consistent with Studies by Shah-hosseini and Hamzehgardesh, (2014) which showed Iranian female adolescents express their health education needs. Uncomfortable relation between mothers and daughters for reasons such as fear of shamefulness and among the various cultural taboos. The method for dealing with reproductive and sexual issues is different in Iran compared to other societies. In Iran, due to some culturaltraditional beliefs, the environment of families is such that does not allow for open discussion of sexual issues. It means that indeed the school children lack the necessary sexual information and as such, the students need health education to promote their sexual and reproductive health.

With regards to this sub-theme 2. Sexually transmitted infections (STI) prevention

At least six out of the 10 participants affirmed that sexually transmitted infections (STI) prevention is a Sexual and Reproductive Health Needs of public-school adolescent girls. These answers concurred with the results of a study conducted by Hoang, Nguyen and Duong (2018), which provides insight into adolescent sexual behaviour and barriers related to cognitive accessibility and psychosocial accessibility of SRH services in Lao PDR. The Narratives of our participants clearly showed that a proportion of the youth is sexually active but are often not taking appropriate precautions to promote themselves and their partners' RHEN. The preventive measures that youth in this study used-often irregularly-were condoms, oral pills and emergency pills, as well as traditional contraceptive methods, such as withdrawal or periodic abstinence.

In addition, in sub-theme 3. contraceptive use and information on appropriate usage

The expression of two participants regarding their unmet needs and knowledge of contraception during the interview was also in consonance with Guttmacher, (2010) study. Guttmacher, (2010) states that, in sub-Saharan Africa, for example, up to 68\% of adolescents have an unmet need for contraception. Not only that contraceptives are not made available to adolescent school girls, facilities and personnel to provide them are also not available.

Under Theme 2: on methods of sexual health dissemination

Two sub-themes also emerged from this theme as viz: information on appropriate usage and the need for the appropriate information. Sub-theme 1: Information on appropriate usage was mentioned by participants on the need for adequate information on appropriate usage of facilities and services as was quoted. This finding is consistent with Ren, Liu, Gao, et al (2015) study, which affirmed the use of appropriate healthcare technologies, the technologies could be information or other evidence-based approaches, in a cross-sectional study in rural Zhejiang of China. The findings demonstrate that appropriate health services information usage demonstrated that AHTs have been widely accepted by the target audience in China, on account of appropriate information on service usage. Although in a different context and other demographic differences, can be applied in this study. What is appropriate information usage, 
it means adopting or utilizing relevant information obtained, which is needed for sexual and reproductive health decision-making. There is a need for adequate information on appropriate usage of facilities and services to improve the adolescents sexual, reproductive health and general well-being is a prerequisite, considering the fact that some people do not know how to use the service. For information to be effectively used, there are different approaches or methods through which the information could be transmitted which participants mentioned counselling as was quoted “. even counselling is needed" (P2).

This response is in consonance with Kabir, (2017) introduction to counselling study which describes counselling as an art and science. It is a short term, interpersonal, theory-based, helping profession. In other words, counselling is a contracted discussion between a client and a counsellor at a set time, in an agreed place and date. In this context, counselling is the service offered to the adolescent who is undergoing sexual and reproductive problems, thus needs professional help to the student overcome them (Kabir, 2017). The benefits are that counselling could help the student to determine the root cause of sexual behavioural issues and focus on re-orienting the student. Thus for participants to mention counselling as an appropriate method to disseminate sexual and reproductive health information is apt because, a counsellor can guide and direct the adolescent students through a variety of situations and help them to focus on what really matters either individually or as a group (Kabir, 2017).

Again, with regards to reaching students with the relevant information, participant three (3) also mentioned the need for students to be given sexual and reproductive health information through either the students reaching out to the providers at the healthcare facility as a method or the healthcare provider reaching out to the students and educate the students. This is also consistent with a study by the Committee on Communication for Behaviour Change in the 21st Century (2002). The study talked on among several other issues in public health communication campaign on national Youth Anti-Drug Media Campaign and describes successes recorded for reaching out to the target audience. That is, in terms of how the outreach affected those audiences. The essence is that reaching out to students or vice versa is crucial as it is impossible to reach every student at once. Reaching out allows the provider to focus health promotion efforts on the groups that are most vulnerable, aimed at generating in an efficient, affordable manner.

In discussing sub-theme 2: The need for appropriate information dissemination. This theme was also stressed by participants. To put it differently, participants reiterated the need to disseminate sexual and reproductive health information as the quote was sampled by (P2) and (P1)

These study findings are also consistent with Ekiyor and Altan (2020) study on "marketing communication in the health sector is the communication of the products or services produced by health organizations to the potential users and convincing them about the benefits to be provided" the study posed it that, health services promotional issues are controversial, however, there are marked differences because promotional activities in health services are different from promotional activities in other sectors. This affirmation indicates the need without missing words that health information must be passed to the adolescent students with regards to their sexual and reproductive health promotion. 
In Conclusion- Findings indicate that the public-secondary school adolescent girls require education on; menstrual cycle, prevention of sexually transmitted infections, Human ImmunoDeficiency Virus /Acquired Immune Deficiency Syndrome, as well as on appropriate use of different types of contraceptives from established centres for sexual and reproductive health services. To ensure the public secondary school girls have access to the services and utilize the services, this study recommends the dare need to adopt different methods to disseminate sexual and reproductive health information to reach the secondary school girls to prevent avertable illnesses and deaths.

\section{Acknowledgements}

The authors would like to thank all participants.

\section{Competing interests}

The authors have declared that no competing interests exist.

\section{Authors' contributions}

H.I.W. supervised the conduct of his study. All authors contributed to the finalization of the article.

\section{Funding information}

This study was not funded.

\section{Data availability statement}

Data sharing does not apply to this article.

\section{REFERENCE}

American Academy of Child and Adolescent Psychiatry (2018). Adolescent Development Part 1 (https://www.aacap.org/AACAP/Families_and_Youth/Facts_for_Families/FFF_ Guide/Normal-Adolescent-Development-Part-I-057.aspx). Accessed 6/09/2021.

Cleveland Clinic Medical Professional (2018). Adolescents Development. https://my.clevelandclinic.org/health/articles/7060-adolescent-development. Accessed 6/09/2021.

Committee on Communication for Behavior Change in the 21st Century (2002). Improving the Health of Diverse Populations. Speaking of health: Assessing health communication strategies for diverse populations. National Academies Press.

Creswell, J. W. (2014). Qualitative, quantitative and mixed methods approach. Sage.

DeLamater, (2018). Sexual expression in later life: a review and synthesis. PMID: 22380585.DOI: 10.1080/00224499.2011.603168.

Demissie Z et al., School Health Profiles 2014: Characteristics of Health Programs Among Secondary Schools, HHS and CDC, 2015, https://www.cdc.gov/healthyyouth/data/profiles/pdf/2014/2014_profiles.

Ekiyor, A., \& Altan, F. (2020). Marketing Communication and Promotion in Health Services. Promotion and Marketing Communications. 
Eko, J. E., Abeshi, C.E., Osonwo, K.O. and Offiong, D.A., (2013). Perception of student, teachers and parents towards sexuality education in Calabar South Local Government Area of Cross River State. Journal of Sociological Research, Vol 4.http://www.dr.org/10.52961j854i2. 3836 Retrieved on 24/4/2017.

Ghafouri, R., and Ofoghi, S. (2016). Trustworthiness and rigour in qualitative research. International Journal of Advanced Biotechnology and Research, 7(4), 19141922.

Guba, E. G., \& Lincoln, Y. S. (1989). Fourth generation evaluation. Sage.

Guttmacher (2010) International Planned Parenthood Federation. Facts on the sexual and reproductive health of adolescent women in the developing world.

Guttmacher Institute fact sheet (2017) American Adolescents' Sources of Sexual Health Information. The main sources from which teens and young adults learn about sexual health. https://www.guttmacher.org/fact-sheet/facts-american-teens-sourcesinformation-about-sex https://www.globalpartnership.org/results/education-datahighlights.

Hajikazemi, M., \& Sadr, M. H. (2014). Stiffness reduction of cracked general symmetric laminates using a variational approach. International Journal of Solids and Structures, 51(7-8), 1483-1493.

Hoang, A., Nguyen, C.Q., and Duong, C.D. (2018). Youth experiences in accessing sexual healthcare services in Vietnam. Culture, Health and Sexuality, 20(5), 545-559.

Ingham-Broomfield, R. (2015). A nurses' guide to qualitative research. Australian Journal of Advanced Nursing, The, 32(3), 34-40.

James, S., Pisa, P. T., Imrie, J., Beery, M. P., Martin, C., Skosana, C., and Delany-Moretlwe, S. (2018). Assessment of adolescent and youth-friendly services in primary healthcare facilities in two provinces in South Africa. BMC health services research, 18(1), 1-10.

Kabir, S M (2017). Introduction to Counselling. Definition of Counseling; Guidance and Counseling; Concepts of Counseling; Notion and Misconceptions about Counseling; Scope of Counseling; Necessity of Counseling; Steps in the counselling.

Kothari, R., Bokariya, P., Singh, S., and Singh, R. (2016). A comprehensive review on methodologies employed for visual evoked potentials. Scientifica, 2016.

Lindberg LD, Maddow-Zimet I and Boonstra H, (2016). Changes in adolescents' receipt of sex education, 2006-2013, Journal of Adolescent Health, 2016, 58(6):621-627, doi:10.1016/j.jadohealth.2016.02.004.

Olfati, F., and Aligholi, S. (2008). A study on educational needs of teenage girls regarding the reproductive health and determination of proper strategies in achieving the target goals in Qazvin. Journal of Inflammatory Diseases, 12(2), 76-82.

Phipps, M. G. (2008). Consequences of inadequate sex education in the United States. Obstetrics and gynaecology, 111(2 Pt 1), 254-255.

Ren, J., Liu, C., Gao, Q. S., Yang, L., Huang, X., \& Guo, Q. (2015). Use of appropriate healthcare technologies: a cross-sectional study in rural Zhejiang of China. BMC health services research, 15(1), 1-9.

Shah-hosseini, Z., and Hamzehgardeshi, Z. (2014). How do Iranian female adolescents express their health education needs: A Needs Assessment with Qualitative Thematic Analysis?

Shakour, M., Salehi, K., and Yamani, N. (2018). Reproductive health need assessment of adolescent boys and girls during puberty: a qualitative study. International Journal of Pediatrics, 6(9), 8195-8205. 
Shiffman, J., Kunnuji, M., Shawar, Y. R., and Robinson, R. S. (2018). International norms and the politics of sexuality education in Nigeria. Globalization and health, 14(1), 1-13.

Simkhada, P., Van Teijlingen, E., Sharma, G., Simkhada, B., and Townend, J. (2012). User costs and informal payments for care in the largest maternity hospital in Kathmandu, Nepal. Health Science Journal, 6(2), 317-334.

UNAIDS. Global AIDS Update Geneva: UNAIDS; 2016.

UNESCO Institute of statistic facts sheet, no.56 (2019). New Methodology Shows that 258.

UNFPA (2014) Adolescent sexual and reproductive health. available at https://www.unfpa.org/resources/adolescent-sexual-and-reproductive-health. Accessed August, $28^{\text {th }} 2021$.

United Nations Development Programme (2021) Sustainable Development Goals Integrated. Available at https://www.undp.org/sustainable-developmentgoals?utm_source $=$ EN\&utm_medium $=$ GSR\&utm_content=US_UNDP. Retrieved 21/08/2021.

United Nations Educational, Scientific and Cultural Organization (UNESCO) (2012). Comprehensive Sexuality Education: The Challenges and Opportunities of Scaling-Up. Paris.

United Nations Population Fund, (UNPFA) (2021). Sexual \& reproductive health. available at https://www.unfpa.org/sexual-reproductive-health. retrieved $24^{\text {th }}$ August 2021.

United Nations. The Global Strategy for Women's, Children's and Adolescents' Health (2016-2030). New York: Every Woman Every Child; 2015.

Wankasi HI and Efeunu, EN 2020. Adolescent Girls` Perception of Sexual and Reproductive health Education in Amassoma Community, Bayelsa State. Dissertation.

Wankasi HI, Jerusalem and Chikwuere CP (2021). Parents` Perception of Sex Education on the Development of Adolescent Secondary School Girl in Gbarantoru Community Bayelsa State: A Descriptive Study. IORS Journal

World Health Organization (2018). Adolescent development available at (http://www.who.int/maternal_child_adolescent/topics/adolescence/development/en/). Accessed 6/09/2021. 